\title{
Chronic venous insufficiency and varicose veins of the lower extremities
}

\author{
Young Jin Youn ${ }^{1,2}$ and Juyong Lee ${ }^{2}$
}

\begin{abstract}
${ }^{1}$ Division of Cardiology, Department of Internal Medicine, Yonsei University Wonju College of Medicine, Wonju, Korea; ${ }^{2}$ Division of Interventional Cardiology, Calhoun Cardiology Center, UConn Health, University of Connecticut School of Medicine, Farmington, CT, USA
\end{abstract}

Received: June 27, 2018

Accepted: September 8, 2018

\author{
Correspondence to \\ Juyong Lee, M.D. \\ Division of Interventional \\ Cardiology, Calhoun Cardiology \\ Center, UConn Health, University \\ of Connecticut School of Medicine, \\ 263 Farmington Av, Farmington, \\ CT 06030 , USA \\ Tel: +1-860-679-2058 \\ Fax: +18606793346 \\ E-mail:jlee@uchc.edu
}

Chronic venous insufficiency (CVI) of the lower extremities manifests itself in various clinical spectrums, ranging from asymptomatic but cosmetic problems to severe symptoms, such as venous ulcer. CVI is a relatively common medical problem but is often overlooked by healthcare providers because of an underappreciation of the magnitude and impact of the problem, as well as incomplete recognition of the various presenting manifestations of primary and secondary venous disorders. The prevalence of CVI in South Korea is expected to increase, given the possible underdiagnoses of CVI, the increase in obesity and an aging population. This article reviews the pathophysiology of CVI of the lower extremities and highlights the role of duplex ultrasound in its diagnosis and radiofrequency ablation, and iliac vein stenting in its management.

Keywords: Diagnosis; Review; Therapeutics; Venous insufficiency

\section{INTRODUCTION}

Chronic venous insufficiency (CVI) of the lower extremities is associated with a wide clinical spectrum, ranging from asymptomatic but cosmetic problems to severe symptoms [1-4]. This includes telangiectases (or spider veins), reticular veins, varicose veins, edema, pigmentation and/or eczema, lipodermatosclerosis, atrophie blanche, and venous ulceration.

CVI is a relatively common medical problem but is often overlooked by healthcare providers because of an underappreciation of the magnitude and impact of the problem, as well as incomplete recognition of the various presenting manifestations of primary and secondary venous disorders [2]. Abnormal venous flows of the lower extremities are observed in up to $50 \%$ of in- dividuals, albeit the estimated prevalence of CVI varies depending on the population studies [5-7].

Advancing age, family history, prolonged standing, obesity, smoking, sedentary lifestyle, lower extremity trauma, prior venous thrombosis, the presence of an arteriovenous shunt, high estrogen states, and pregnancy are all considered risk factors for CVI [5,8-13]. Although the prevalence of CVI in the Asian population is significantly lower compared with non-Hispanic whites according to a multiethnic cross-sectional study [14], the prevalence of CVI in South Korea is expected to increase due to the possible underdiagnosis of CVI, the increase in obesity, and an aging population. This article reviews the pathophysiology of CVI of the lower extremities and highlights the role of duplex ultrasound (DUS) in its diagnosis, and radiofrequency ablation 


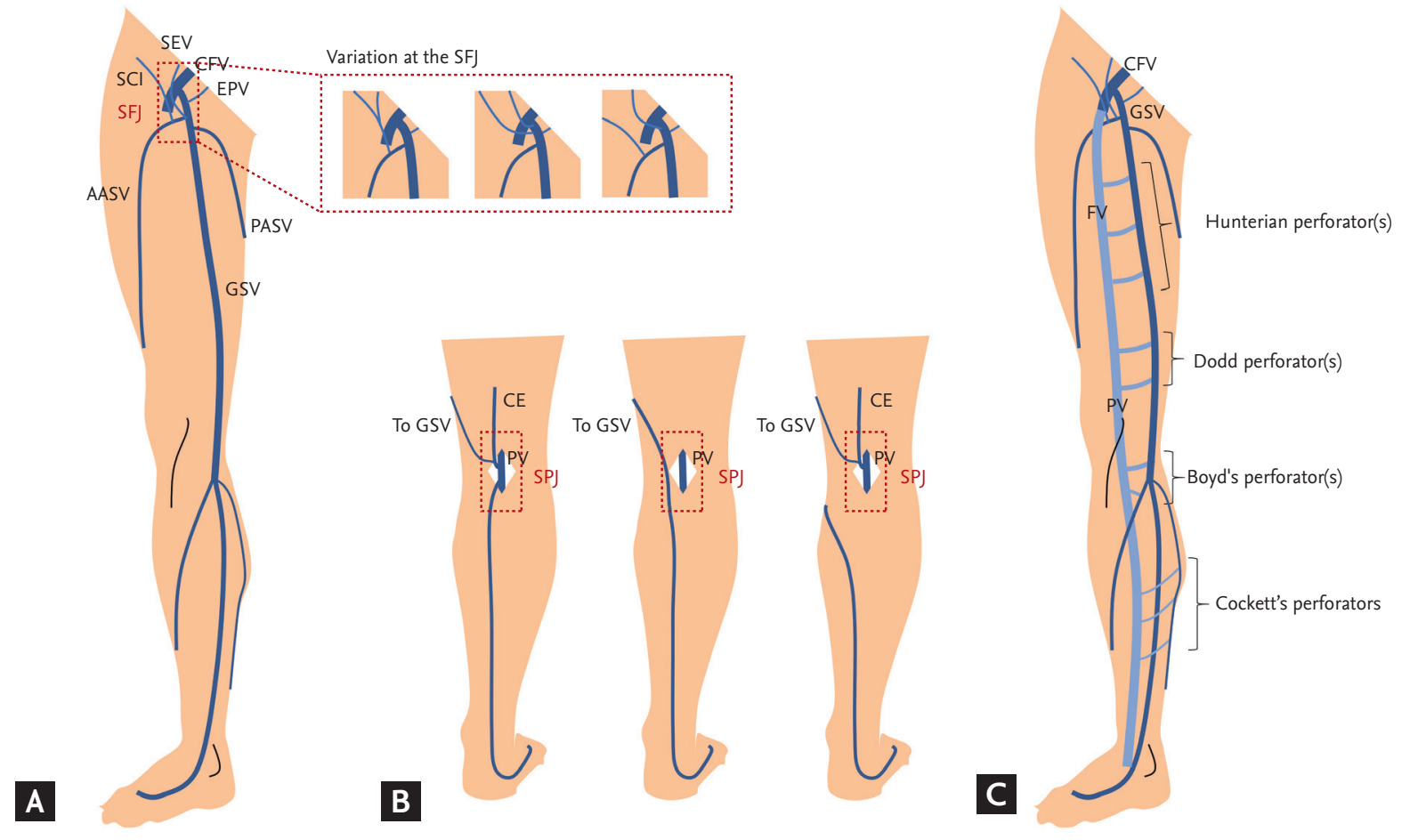

Figure 1. Venous system of the lower limb. (A) Great saphenous vein and its tributaries. (B) Small saphenous vein and its variations. (C) Perforating veins. SEV, superficial epigastric vein; SCI, superficial circumflex iliac vein; CFV, common femoral vein; EPV, external pudendal vein; SFJ, saphenofemoral junction; AASV, anterior accessory of the great saphenous vein; PASV, posterior accessory of the great saphenous vein; GSV, great saphenous vein; CE, cranial extension of the small saphenous vein; PV, popliteal vein; SPJ, saphenopopliteal junction; FV, femoral vein.

(RFA) and iliac vein stenting in its management.

\section{PATHOPHYSIOLOGY}

The main pathophysiological cause of the clinical manifestation of CVI of the lower extremities is ambulatory venous hypertension, which is caused by venous valve reflux, venous flow obstruction, or both [2]. The venous pressure of the foot vein in the standstill position without skeletal muscle contraction is as high as 80 to 90 mmHg. In a subject with competent venous valves, this pressure decreases to less than $30 \mathrm{mmHg}$ during ambulation [15]. However, in a patient with CVI, the decrease in venous pressure with leg movements is attenuated. If valves in the perforator veins are incompetent, the high pressures generated in the deep veins by calf-muscle contraction can be transmitted to the superficial system and to the microcirculation in skin. This is called ambulatory venous hypertension. Postthrombotic syndrome after deep vein thrombosis (DVT) also causes venous hypertension due to the remaining obstruction of the venous flow and valvular reflux due to valve damage [16].

\section{VENOUS ANATOMY AND ITS VARIATIONS}

To understand the pathophysiology of CVI or varicose veins as well as their therapeutic options, such as endovenous ablations, one should know the anatomy and variations of the veins. The consensus on the nomenclature of anatomic terminology was established by an International Interdisciplinary Committee in 2001 and $2005[17,18]$. The venous system can be divided into three major components: the superficial venous system, the deep venous system, and perforating veins.

\section{Superficial venous system}

The superficial venous system drains the blood flow from the skin and the subcutaneous tissues (Fig. 1). Historically, any veins located above the deep muscular fascia, which are not deep veins, are considered 

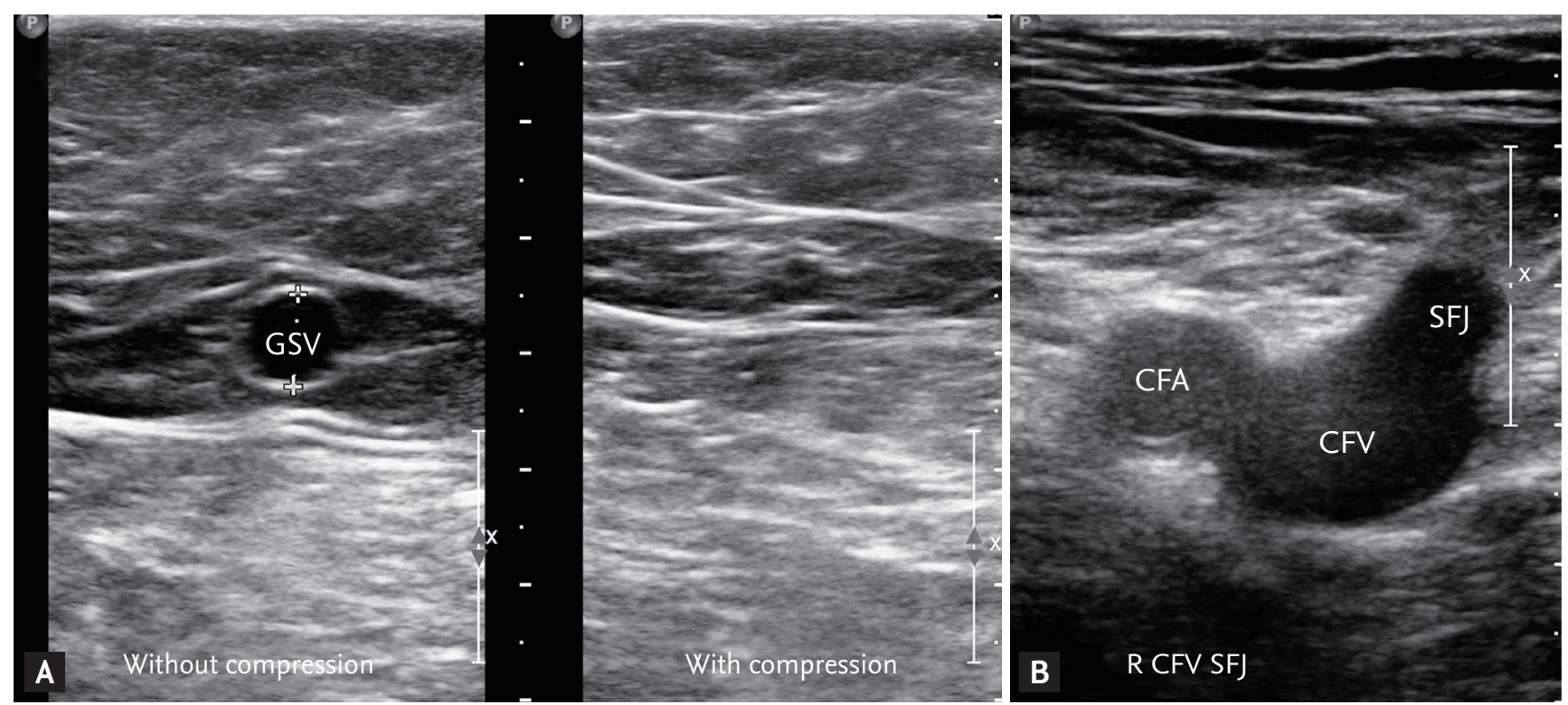

Figure 2. Sonographic landmark of superficial femoral veins. (A) The 'Egyptian eye': a transverse ultrasound image of the great saphenous vein in the thigh with/without compression showing the fascial components that constitute the saphenous compartment. (B) Transverse view of the common femoral vein (CFV) and artery in the right groin: 'Mickey mouse' view. GSV, great saphenous vein; CFA, common femoral artery; SFJ, saphenofemoral junction.

superficial veins. The superficial venous system can be divided into thick-walled truncal veins, such as the great saphenous vein (GSV) and the small saphenous vein (SSV), which lie between the saphenous sheath and the muscular fascia, and the thin-walled superficial or epifascial tributaries, which lie between the skin and saphenous fascia $[19,20]$. This relationship between veins and sheath or fascia looks like an Egyptian eye on the ultrasound (Fig. 2A). It is used as a key marker to identify the saphenous veins. However, only $50 \%$ of patients have the saphenous trunk located throughout the entire saphenous compartment from the ankle to the groin [19,21].

The GSV is the longest vein in the body (Fig. 1A). It originates on the medial side of the foot and ascends anterior to the medial malleolus and then along the medial side of the calf and thigh and drains into the common femoral vein (CFV) $[18,22]$. In the tibial part, the GSV is joined by two tributaries: the posterior accessory of the great saphenous vein (PASV; previously called the vein of Leonardo) and the anterior accessory of the great saphenous vein (AASV). Clinically, the PASV is important in patients with venous ulceration because the posterior tibial perforators (previously called Cockett) connect the posterior tibial veins and the PASV, but not the distal GSV.
The saphenofemoral junction (SFJ or saphenous junction or saphenous arch) is a critical area in terms of understanding flow patterns, treatment approaches, and the recurrence of varicosities. Using DUS, the "Mickey mouse" sign (Fig. 2B) can be used as a landmark consisting of the common femoral artery, CFV, and GSV. The SFJ includes the area between the terminal and preterminal valves of the CFV and three major tributaries draining in the GSV: the external pudendal, inferior epigastric, and external circumflex iliac veins. Regarding endovenous ablation, leaving the superficial inferior epigastric vein intact is believed to reduce the incidence of endovenous heat-induced thrombus (EHIT) extension into the femoral vein. The anatomic variation of the SFJ is significant [3]. A major distal tributary of the SFJ is the AASV. Approximately half of patients have the AASV. Because the AASV can be a source of recurrent varicose veins, it is important in diagnosis and treatment [23].

The SSV originates on the dorsolateral aspect of the foot, ascends posterior to the lateral malleolus and along the posterolateral aspect of the calf, and drains into the popliteal vein (Fig. 1B). The saphenopopliteal junction (SPJ), where the SSV joins the popliteal vein, shows variability. Cranial extension (CE) of the SSV is 
present in $95 \%$ of limbs and is the continuation of the SSV. However, in approximately $25 \%$ of limbs, the SSV does not have a connection to the deep vein but continues up the posterior thigh as the CE. The location of the SPJ is located above the popliteal crease, but is far above the popliteal crease in $25 \%$ of limbs $[20,24]$.

\section{Deep venous system}

The deep venous system is a low pressure, high volume system that is responsible for approximately $90 \%$ of the venous blood flow in the lower extremities. Deep veins usually have a thinner wall than superficial veins. However, they are supported by the muscle and/or fascia. This forms a rigid compartment and makes a vein pump the venous blood flowing upwards during walking. All deep veins follow corresponding arteries in general except on the distal side of the intramuscular veins (soleal and gastrocnemius). The anterior and posterior tibial vein, peroneal vein, soleal vein, and gastrocnemius vein are located in the infrapopliteal area. The main function of the deep venous system is to provide a venous return to the right heart.

The veins of the pelvis consist of three major vessels: the external iliac vein, the internal iliac vein, and the common iliac vein. Obstruction in the iliac vein plays a significant role in CVI. After DVT, only $20 \%$ to $30 \%$ is fully recanalized, and residual obstruction is associated with severe CVI $[25,26]$. This type of occlusion is categorized as a thrombotic occlusion. This can be treated with a stent, but the patency of this type of lesion is inferior to that of non-thrombotic occlusion [27]. In contrast, non-thrombotic iliac vein lesions, such as stenosis, can also cause CVI. An Iliac vein compression syndrome (or May-Thurner syndrome) is a clinical condition that occurs as a result of compression of the left iliac vein between the right iliac artery and the fifth lumbar vertebrae $[28,29]$. Even though such lesions can be found in half of the asymptomatic population, the clinical sequelae, such as DVT or CVI, are only observed in approximately $3 \%$ to $5 \%$ of patients [30,31]. Pelvic CVI, defined as retrograde flow in the gonadal and internal iliac veins, is the underlying cause of pelvic congestion syndrome, a common cause of disabling chronic pelvic pain in women of child-bearing age, and endovascular embolization has become the treatment of choice for this syndrome [32].

\section{Perforating vein}

Perforators are bridging channels between the superficial and deep venous systems (Fig. 1C). These veins obliquely perforate the deep fascia and play a key role in equilibrating blood flow during calf muscle contraction because of valves that prevent reflux from the deep venous system to the superficial venous system. Perforating veins are numerous and highly variable in arrangement, connection, and size. There are four clinically important perforator groups: upper thigh (Hunterian), lower thigh (Dodd's), at knee level (Boyd's), and in the calf region (Cockett's). Although perforator valve incompetence is always associated with CVI [33], the cause of perforator insufficiency is not known, and the routine treatment of perforating veins in $\mathrm{C} 2$ patients is not supported [3].

\section{Vein valves}

In the standing position, blood within the lower extremity venous system must overcome gravity and intra-abdominal pressure to return to the circulation. Accordingly, the valves within the venous system are essential in maintaining the blood flow in the correct direction.

Normal venous valves are typically bicuspid and unidirectional. These valves can be found in a vein that is typically slightly dilated. They maintain the blood flow from peripheral to central and ultimately into the right heart. Dysfunction of these valves causes venous reflux or retrograde flow, which can be seen in patients with CVI. The number of venous valves increases from the proximal to distal to prevent an increase in pressure within the distal veins because of gravitational effects [2]. Perforating veins also have valves to prevent reflux from the deep venous system to the superficial venous system. However, the veins of the foot and iliac veins have no valves. The GSV has at least six valves and the SSV has 7 to 10 valves. Tibial veins have as many as valves every $2 \mathrm{~cm}[34,35]$.

The calf muscle pump is also important for venous competence. The calf muscle pump is called the peripheral heart. Through contraction of the calf muscle, the veins are squeezed and the blood is pumped upward in keeping with the one-way valves [36]. During ambulation, the calf muscle pump empties the venous system and the pressure within the veins decreases. Re- 
laxation of the muscle pump then allows blood to refill to the deep venous system. Dysfunction of the valve of the superficial venous system, the deep venous system, the perforating veins or venous tributaries causes CVI by allowing a retrograde flow of blood, which is called "venous reflux." Superficial vein reflux accounts for $90 \%$ of patients presenting with CVI [37].

\section{CLINICAL PRESENTATION}

Clinical features of CVI include discomfort, swelling, varicose veins, and skin changes or ulceration. Venous leg discomfort is often described as a dull ache, throbbing or heaviness, or pressure sensation after prolonged standing and is relieved by any measure that lowers venous pressure, such as elevation of the leg, compression stockings, or walking. However, leg discomfort is absent in an estimated $20 \%$ of patients with other clinical features of CVI, whereas it is the only clinical feature in approximately $10 \%$ of patients [1]. In patients with varicose veins, tenderness could be present because of venous distension. In patients with deep vein obstruction, venous claudication can be present.

Leg edema is a common feature of CVI. It is usually pitting and varies markedly with the time of day and orthostasis [38]. It begins in the perimalleolar area and ascends the leg. Bilateral leg edema can be caused by congestive heart failure, hypoalbuminemia secondary to nephrotic syndrome or severe hepatic disease, myxedema caused by hypothyroidism, and drugs such as dihydropyridine calcium channel blockers and thiazolidinediones. Non-pitting leg edema by lipedema, which is caused by fat deposition, should also be considered. Lipedema does not have feet involvement. It is sometimes difficult to differentiate clinically from lymphedema (phleboedema). Stemmer's sign is one of the clinical features of lymphedema. In addition, up to one-third of CVI cases cause secondary lymphedema, but this secondary lymphedema (phlebolymphedema) may resolve if underlying CVI is corrected.

Varicose veins are dilated, bulging, superficial veins, measuring at least $3 \mathrm{~mm}$ in diameter that become progressively more tortuous and enlarged. Patients with varicose veins are often asymptomatic but still concerned about the cosmetic appearance of their legs.
They cause pain if superficial thrombophlebitis develops and can cause prolonged bleeding.

Cutaneous changes include skin hyperpigmentation, stasis dermatitis, and ulceration. Hyperpigmentation is caused by hemosiderin deposition. Hyperpigmentation in nonvenous conditions, such as acanthosis nigricans or hemosiderosis, is more diffuse or involves other areas of the body. Stasis dermatitis should be differentiated from psoriasis, periarteritis nodosa or allergic dermatitis. Lipodermatosclerosis is a type of inflammation of subcutaneous fat. A venous ulcer can be differentiated from an ischemic ulcer; ischemic ulcers are deeper than venous ulcers and often have gangrenous edges or a gangrenous base.

\section{CLASSIFICATION}

The CEAP (clinical, etiologic, anatomic, pathophysiological) system incorporates a range of symptoms and signs of chronic venous disorders to characterize its severity (Table 1). It also broadly categorizes the etiology as congenital, primary, or secondary; identifies the affected veins as superficial, deep, or perforating; and characterizes the pathophysiology as reflux, obstruction, both, or neither. However, this system is not useful for venous severity scoring because many of its components are relatively static and others use detailed alphabetical designations. An adjunctive scoring system (Table 2) allows for a standardized clinical evaluation, the assessment of clinical severity, and evaluation of the response to treatment [39-41].

\section{DIAGNOSIS}

A complete history and physical examination are important to establish a proper diagnosis of CVI. Physical examination should be evaluated in the upright position to allow for maximal distension of the veins. Non-invasive and invasive diagnostic testing must assist the diagnosis. The methods used to assess CVI are described below, but DUS will be highlighted and others will be reviewed briefly. Comprehensive overviews have been published previously [42]. 
Table 1. CEAP classification of chronic venous disorders

\begin{tabular}{|c|c|}
\hline \multicolumn{2}{|c|}{ Clinical classification $(\mathrm{C})^{\mathrm{a}}$} \\
\hline $\mathrm{C}_{\mathrm{o}}$ & No visible sign of venous disease \\
\hline $\mathrm{C}_{1}$ & Telangiectases or reticular veins \\
\hline $\mathrm{C}_{2}$ & Varicose veins \\
\hline $\mathrm{C}_{3}$ & Edema \\
\hline \multirow{3}{*}{$\mathrm{C}_{4}$} & Changes in skin and subcutaneous tissue ${ }^{b}$ \\
\hline & (A) Pigmentation or eczema \\
\hline & (B) Lipodermatosclerosis or atrophie blanche \\
\hline $\mathrm{C}_{5}$ & Healed ulcer \\
\hline $\mathrm{C}_{6}$ & Active ulcer \\
\hline \multicolumn{2}{|c|}{ Etiologic classification $(\mathrm{E})$} \\
\hline $\mathrm{E}_{\mathrm{c}}$ & Congenital (e.g., Klippel-Trenaunay syndrome) \\
\hline $\mathrm{E}_{\mathrm{p}}$ & Primary \\
\hline $\mathrm{E}_{\mathrm{s}}$ & $\begin{array}{l}\text { Secondary (e.g., postthrombotic syndrome, } \\
\text { trauma) }\end{array}$ \\
\hline $\mathrm{E}_{\mathrm{n}}$ & No venous cause identified \\
\hline \multicolumn{2}{|c|}{ Anatomic classification $(\mathrm{A})$} \\
\hline $\mathrm{A}_{\mathrm{s}}$ & Superficial \\
\hline$A_{d}$ & Deep \\
\hline$A_{p}$ & Perforator \\
\hline $\mathrm{A}_{\mathrm{n}}$ & No venous location identified \\
\hline \multicolumn{2}{|c|}{ Pathophysiologic classification $(\mathrm{P})$} \\
\hline $\mathrm{P}_{\mathrm{r}}$ & Reflux \\
\hline $\mathrm{P}_{\mathrm{o}}$ & Obstruction, thrombosis \\
\hline $\mathrm{P}_{\mathrm{r}, \mathrm{o}}$ & Reflux and obstruction \\
\hline $\mathrm{P}_{\mathrm{n}}$ & No venous pathophysiology identified \\
\hline
\end{tabular}

CEAP, clinical, etiologic, anatomic, pathophysiological.

${ }^{\mathrm{a}}$ The descriptor A (asymptomatic) or S (symptomatic) is placed after the $\mathrm{C}$ clinical class.

${ }^{\mathrm{b}} \mathrm{C}_{4}$ is subdivided into $\mathrm{A}$ and $\mathrm{B}$, with $\mathrm{B}$ indicating higher severity of disease and having a higher risk for ulcer development.

\section{Brodie-Trendelenburg test}

The Brodie-Trendelenburg test is helpful for distinguishing between deep and superficial reflux. The patient lies down and the leg is elevated to empty the veins. Next, a tourniquet or manual compression over the superficial veins is placed and the veins are observed after the patient is asked to stand. Filling of the varicose veins $>20$ seconds indicates that the varicose veins are caused by superficial venous insufficiency. In contrast, the varicose veins will dilate promptly in the presence of deep (or combined) venous insufficiency [2].

\section{Plthysmography}

Plethysmography is a non-invasive venous test that measures each potential component of the pathophysiologic mechanisms of CVI, including reflux, obstruction, and muscle pump dysfunction. Venous volume, venous refilling times, maximum venous outflow, segmental venous capacitance, and ejection fraction can be determined $[43,44]$. There are four basic types of plethysmography: impedance plethysmography, straingauge plethysmography, photoplethysmography, and air plethysmography. Because of its complexity of use, the use of this technique is limited to academic or hospital settings when DUS does not provide definitive information on the pathophysiology of CVI.

\section{Computed tomography and magnetic resonance venography}

Although advancements in computed tomography (CT) and magnetic resonance (MR) images have allowed for better evaluation of venous disease [45-48], these techniques are rarely required to determine the cause and plan treatment for CVI. Appropriate timing of image acquisition based on venous filling time is required to acquire optimal images and avoid artifacts in a certain venous system. In addition, these techniques do not provide functional information. However, these techniques are most useful to evaluate focal or complex lesions located at proximal veins and their surrounding structures and to assess for intrinsic or extrinsic obstruction [41].

\section{Venous duplex ultrasonography}

DUS is currently the most common and useful diagnostic technique for CVI and provides etiological and anatomical information [41]. DUS uses a combination of B-mode imaging and spectral Doppler to detect the presence of venous obstruction and venous reflux in superficial and deep veins. Color-assisted DUS is useful for visualizing venous flow patterns.

\section{Diagnosis of venous obstruction}

The diagnosis of venous obstruction can be inferred from the absence of flow, blunted augmentation, the presence of an echogenic thrombus within the vein, or failure of the vein to collapse by a compression maneuver (Fig. 3). Large veins such as the inferior vena cava, 
Table 2. Venous Clinical Severity Score

\begin{tabular}{|c|c|c|c|c|}
\hline Attribute & Absent $=0$ & Mild = 1 & Moderate $=2$ & Severe $=3$ \\
\hline Pain & None & $\begin{array}{l}\text { Occasional, not restricting } \\
\text { daily activity }\end{array}$ & $\begin{array}{l}\text { Daily, interfering but not } \\
\text { preventing daily activity }\end{array}$ & $\begin{array}{l}\text { Daily, limits most daily } \\
\text { activity }\end{array}$ \\
\hline Varicose veins & None & $\begin{array}{l}\text { Few, isolated branch varices, } \\
\text { or clusters, includes ankle } \\
\text { flare }\end{array}$ & Confined to calf or thigh & Involves calf and thigh \\
\hline Venous edema & None & Limited to foot and ankle & $\begin{array}{l}\text { Extends above the ankle but } \\
\text { below knee }\end{array}$ & Extends to knee and above \\
\hline Skin pigmentation & None or focal & Limited to perimalleolar & $\begin{array}{l}\text { Diffuse, over lower third of } \\
\text { calf }\end{array}$ & $\begin{array}{l}\text { Wider distribution above } \\
\text { lower third of calf }\end{array}$ \\
\hline Inflammation & None & $\begin{array}{l}\text { Mild cellulitis, ulcer margin } \\
\text { limited to perimalleolar }\end{array}$ & $\begin{array}{l}\text { Diffuse over lower third of } \\
\text { calf }\end{array}$ & $\begin{array}{l}\text { Wider distribution above } \\
\text { lower third of calf }\end{array}$ \\
\hline Induration & None & Limited to perimalleolar & $\begin{array}{l}\text { Diffuse over lower third of } \\
\text { calf }\end{array}$ & $\begin{array}{l}\text { Wider distribution above } \\
\text { lower third of calf }\end{array}$ \\
\hline Ulcer number & o & 1 & 2 & $\geq 3$ \\
\hline Ulcer duration & NA & $<3$ mon & $>3$ mon but $<1$ yr & Not healed > 1 yr \\
\hline Ulcer size & NA & Diameter $<2 \mathrm{~cm}$ & Diameter $2-6 \mathrm{~cm}$ & Diameter $>6 \mathrm{~cm}$ \\
\hline Compressive therapy & Not used & Intermittent & Most days & Full compliance \\
\hline
\end{tabular}

An aggregate score for the limb is calculated by adding the individual component scores. The range of the total score is o to 30 . NA, not applicable.

iliac, femoral, and popliteal vessels show spontaneous blood flow at rest. This flow reflects respiratory changes (Fig. 4A). Normal flow stops during inspiration and returns during expiration because of the increased intra-abdominal pressure during inspiration. Small veins, such as calf veins, usually do not show spontaneous flow because of their size. An absence of spontaneous flow may indicate an obstruction either proximal or distal to the area of examination. In addition, nearly constant high velocity flow without significant respiratory changes indicates a proximal stenosis or occlusion (Fig. 4B). Spontaneous flow should be evaluated in a supine or slight reverse Trendelenburg position, not standing position. Augmentation by applying a moderately firm squeeze over the calf to increase flow moving centrally can be evaluated in normal veins. When performing a compression, it is best to squeeze and hold for approximately 0.25 second and then release. This maneuver is used to confirm the patency of the vein segment. Blunting of augmentation suggests obstruction. However, the major limitation of this maneuver is the variability of the force of the compression. Compressibility is the most reliable way of diagnosing an intraluminal thrombus and this technique is performed in a short-axis view. Iliac vein non-thrombotic stenosis can be seen by the increased blood velocity from DUS at the iliac veins (Fig. 5).

\section{Diagnosis of venous reflux}

Venous reflux is detected by the direction of flow. Any significant reverse flow toward the foot is considered venous reflux (Fig. 6). Venous reflux is assessed in the reverse Trendelenburg position. Although reverse flow can be detected without the provocation maneuver, the Valsalva maneuver or augmentation by compressing the calf can be used to confirm venous reflux. The Valsalva maneuver increases intra-abdominal pressure. The primary goal of this test is to evaluate the flow characteristics and valve functions in the central vessels. Downward pressure is transmitted down and through the dysfunctional valves until it reaches the functioning valve. Prolonged reversal flow after augmentation suggests venous reflux. However, the preferred provocation maneuver is the use of a cuff inflation-deflation technique with rapid cuff deflation in the standing position [49]. This technique provides more uniform quantifiable results for detecting reflux in the superficial and deep veins of the leg. The duration of reflux is 

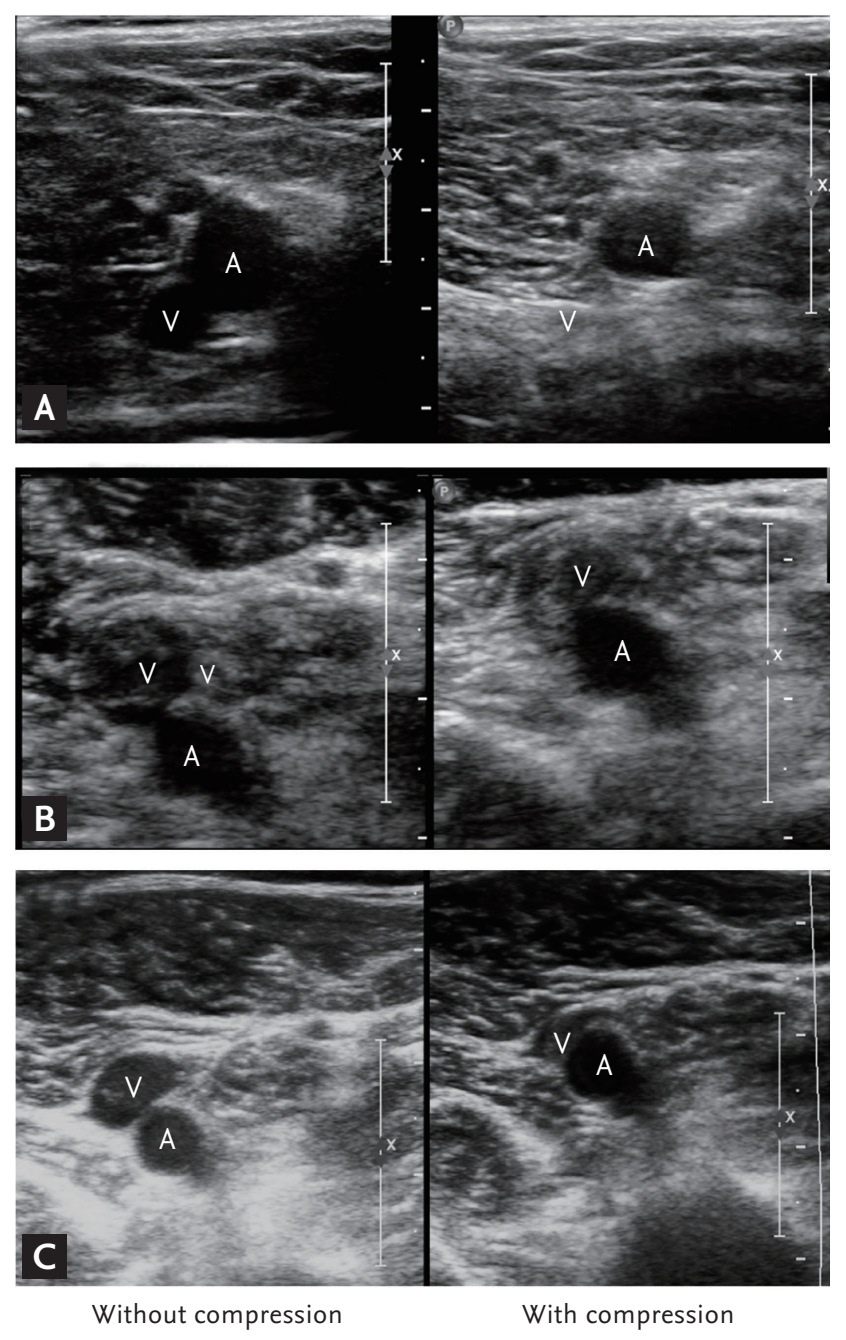

Figure 3. Sonographic evaluation of compressibility. (A) Compressible popliteal vein without echogenic thrombus within the normal vein. (B) Uncompressible enlarged popliteal vein with echogenic thrombus in acute deep vein thrombosis. (C) Partially compressible popliteal vein with partially recanalized echogenic thrombus within the lumen in chronic deep vein thrombosis. A, artery; V, vein.

called the reflux time. Brisk venous reflux is considered normal. The values currently accepted for pathologic reflux are $>1.0$ second in the femoral or popliteal veins, $>0.5$ second in the saphenous systems, and $>0.35$ in the perforators [50]. Although the duration of reflux reflects the severity of disease, it does not correlate with clinical manifestations [51].

DUS examination in patients with CVI should demonstrate both the anatomical patterns of veins and abnormalities of venous blood flow in the limbs. The following data should be established [50]: (1) which saphenous junctions are incompetent, their locations and diameters; (2) the extent of reflux in the saphenous veins of the thighs and legs and their diameters; the number, location, diameter, and function of incompetent perforating veins; (3) other relevant veins that show reflux; (4) the source of filling of all superficial varices if not from the veins already described; (5) veins that are hypoplastic, atretic, absent, or have been removed; and (6) the state of the deep venous system including the competence of valves and evidence of previous venous thrombosis.

\section{Intravascular ultrasound}

Because venous intravascular ultrasound (IVUS) is superior to conventional venography for the morphologic diagnosis of iliac venous outflow obstruction (Fig. 7) and an invaluable assistance in the accurate placement of venous stents, IVUS is rapidly gaining acceptance in venous percutaneous intervention, in the treatment of chronic venous iliofemoral disease [52,53].

\section{TREATMENT}

All patients with signs and/or symptoms of CVI should be initially treated with conservative management. The use of compression stockings is the mainstay of conservative management. However, risk modification, such as weight reduction in an obese patient, regular walking exercise, and cessation of smoking, should also be encouraged in the patient as conservative management. The overview of the diagnosis and treatment of CVI is well-illustrated by Eberhardt and Raffetto [2].

\section{Compression stockings}

The objective of compression stockings is to provide graded external compression to the leg and oppose the hydrostatic forces of venous hypertension $[54,55]$. Compression stockings with graduated compression are preferred over nongraded compression stockings. There is no difference between knee-length versus thigh-length graduated compression stockings for the prevention of DVT in postoperative patients [56]. Kneelength stockings are tolerated better by most patients, particularly elderly patients.

Stockings with compression pressure between 20 and 

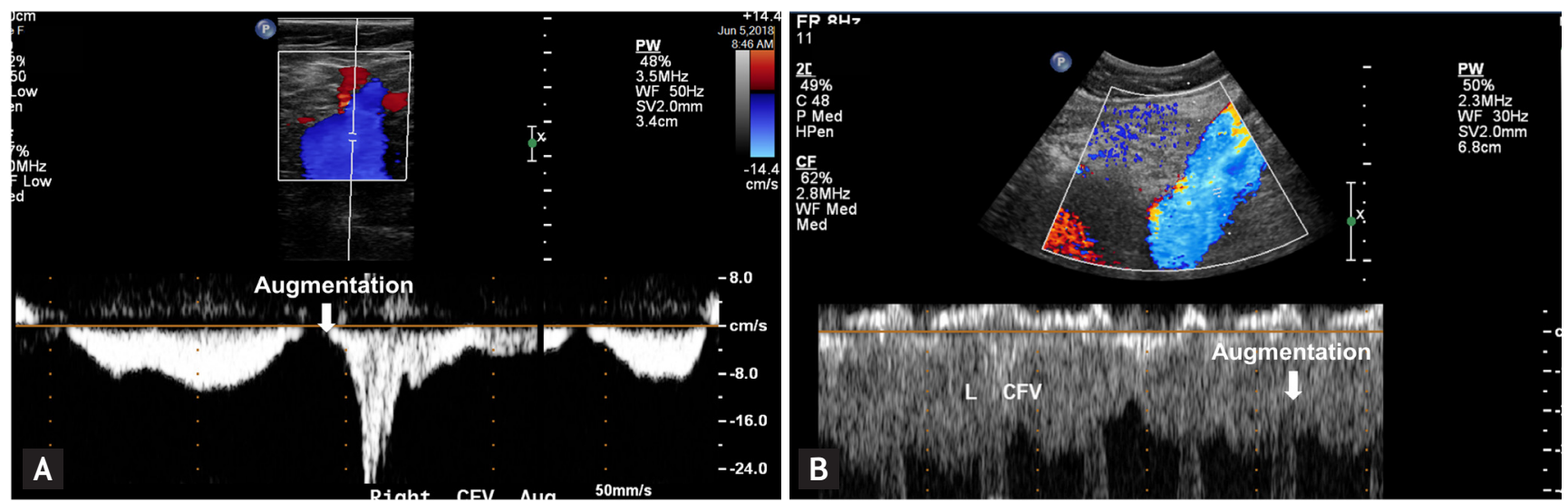

Figure 4. Doppler ultrasound of the femoral veins. (A) Spontaneous blood flow with respiratory changes and normal response to an augmentation maneuver. (B) Nearly constant high velocity flow without significant respiratory changes indicate a proximal stenosis or occlusion. CFV, common femoral vein.
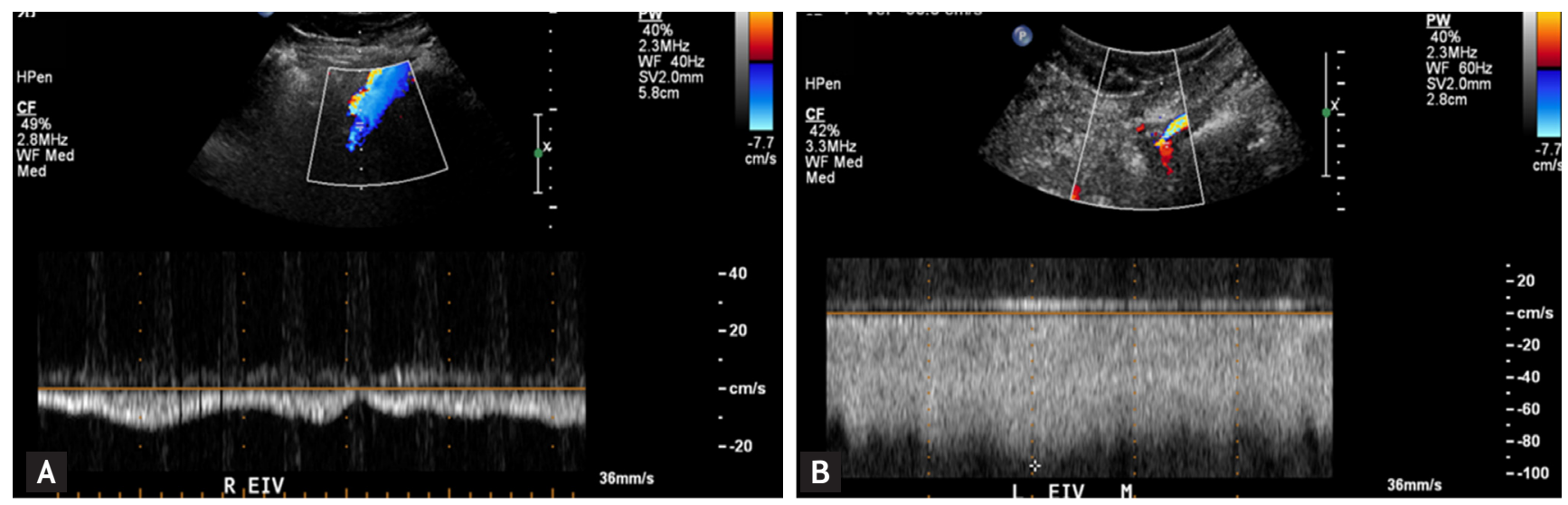

Figure 5. Doppler ultrasound of the iliac veins in a patient with right left iliac vein non-thrombotic stenosis. (A) Normal spontaneous blood flow with respiratory changes at the right external iliac vein (EIV). (B) Increased iliac vein velocity at the left EIV.
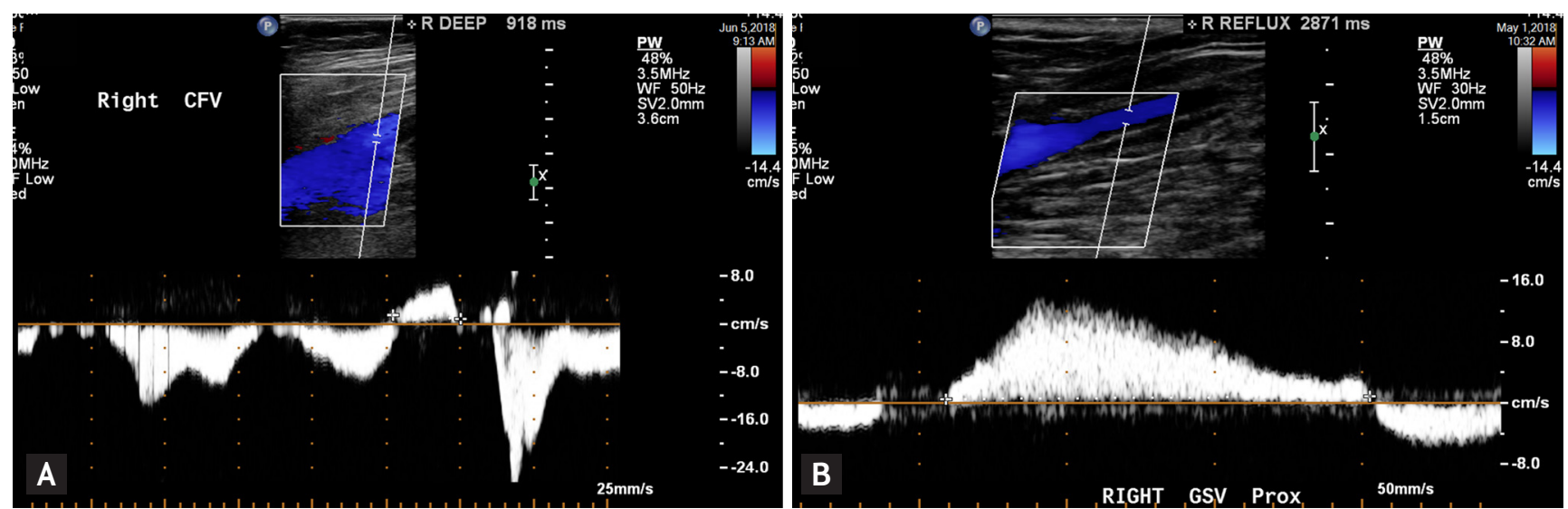

Figure 6. Venous reflux after manual augmentation. (A) Non-pathologic brisk reflux after the augmentation maneuver (reflux time $<1$.0 second in the femoral vein). (B) Pathologic reflux after the augmentation maneuver (reflux time $>0.5$ second in the great saphenous vein). CFV, common femoral vein; GSV, great saphenous vein. 

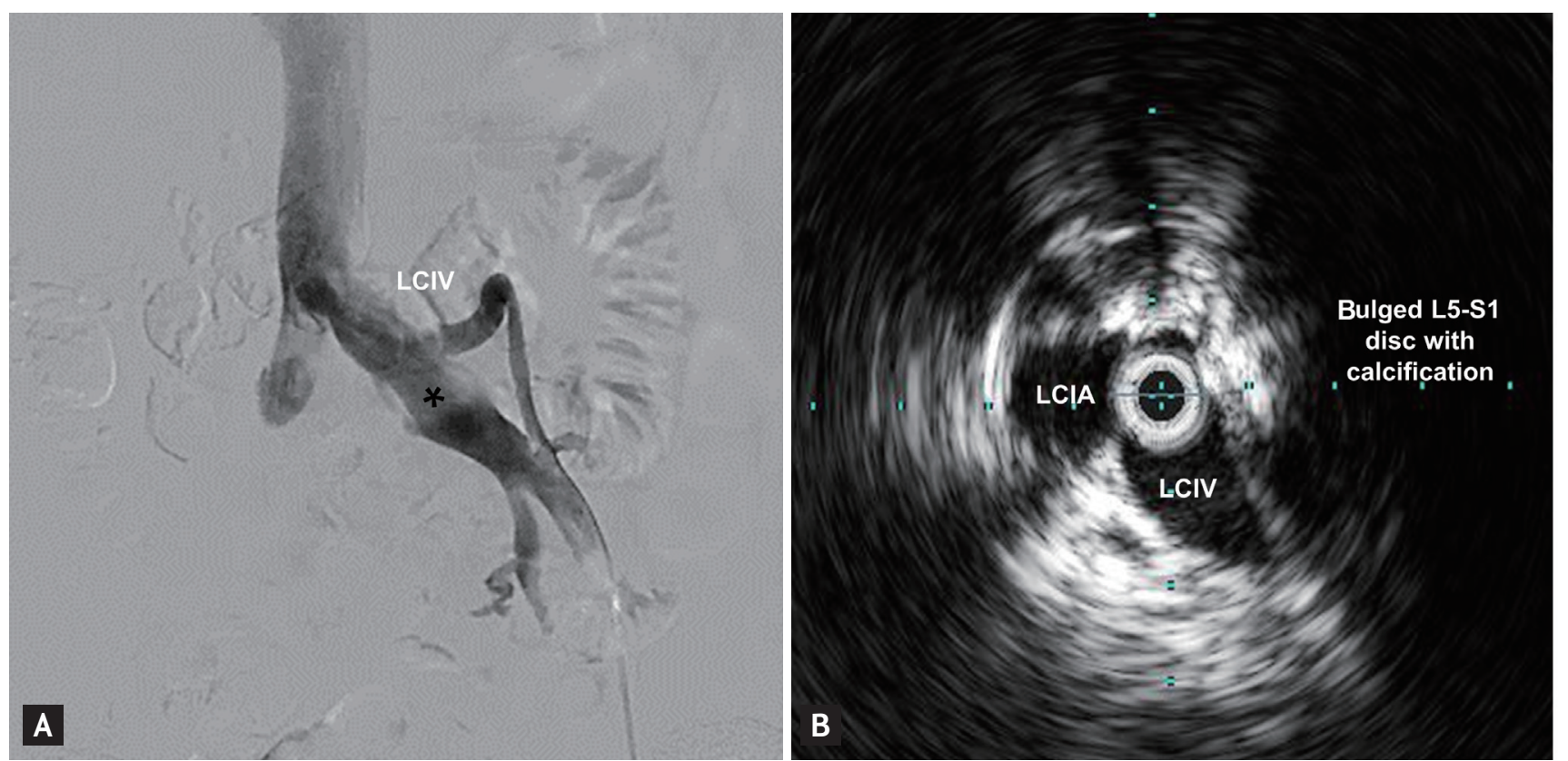

Figure 7. Venography and corresponding intravascular ultrasound (IVUS) of the narrowest lesion. (A) Left common iliac vein (LCIV) shows luminal haziness (black asterisk), pre-stenotic dilatation, and collateral flows on the venography obtained at digital subtraction angiography. (B) IVUS at this lesion reveals that LCIV is compressed by a calcified extrinsic mass that originated from the bulged L5-Si disc with calcification. LCIA, left common iliac artery.

$30 \mathrm{mmHg}$ are recommended for patients with varicose veins with or without edema ( $\mathrm{C}_{2}$ to $\mathrm{C}_{3}$ ). Stockings with a pressure between 30 and $40 \mathrm{mmHg}$ are recommended for patients with advanced venous skin change or an ulcer ( $\mathrm{C}_{4}$ to $\left.\mathrm{C} 6\right)$. In patients with a recurrent ulcer, stockings with a pressure between 40 and $50 \mathrm{mmHg}$ are recommended [41].

Current clinical practice guidelines suggest compression therapy using moderate pressure (20 to $30 \mathrm{mmHg}$ ) for patients with symptomatic varicose veins who are not candidates for saphenous vein ablation. In addition, compression therapy is recommended as the primary therapeutic modality for healing venous ulcers and as an adjuvant treatment to superficial vein ablation for the prevention of ulcer recurrence.

Despite the clinical effectiveness of compression stockings, there are many limitations to their application, including application difficulty (frailty or arthritis), physical constraints (obesity, contact dermatitis, tender, fragile, or weepy skin), and coexisting arterial insufficiency [1]. According to many articles, approximately half of patients cannot continue compression therapy [57-61] for a variety of stated reasons, such as tightness and warmth.

\section{Medical therapy}

Venoactive drugs can be considered for the treatment of symptomatic varicose veins, ankle swelling, and venous ulcers [41]. Many compounds have been tried with varying success, but the most promising drugs are saponins (e.g., horse chestnut seed extract [aescin]) [62], gamma-benzopyrenes (flavonoids) (e.g., rutosides, diosmin, and hesperidin [63]), the micronized purified flavonoid fraction (MPFF) [64], and other plant extracts (e.g., French maritime pine bark extract). The principle for using these venoactive drugs is to improve venous tone and capillary permeability, but the precise mechanism of action of these drugs is unknown. A Cochrane meta-analysis concluded there is insufficient evidence to support the global use of venoactive drugs in the treatment of CVI [65].

Pentoxifylline is a drug that targets inflammatory cytokine release, leukocyte activation, and platelet aggregation at the microcirculatory level. In a meta-analysis of five trials, the use of pentoxifylline in combination with compression was associated with improved healing rates of venous ulcers compared with compression and placebo [66], although the magnitude of the effect appears to be small and its role in patient management 
is unclear. A higher dose of pentoxifylline was more effective than the lower dose, but the higher dose had more significant gastrointestinal upset [67].

Current clinical practice guidelines suggest the use of venoactive drugs such as flavonoids, MPFF, and horse chestnut seed extract to relieve pain and swelling due to CVI and the use of pentoxifylline (400 mg orally three times a day) or MPFF in combination with compression to accelerate the healing of venous ulcers [41].

\section{Surgical therapy}

Open surgical therapy of varicose veins with high ligation and stripping of the GSV combined with the excision of large varicose veins has been the standard of care for more than a century. This therapy is performed in the following sequence: incisions are made in the groin and upper calf; the GSV is ligated (high ligation) below the SFJ, and a wire is inserted into the GSV and advanced distally; the proximal part of the GSV is secured to the wire and retrieved (stripping) via the calf incision. Stripping of the GSV below the knee and stripping of the SSV are not usually performed because of the high risk of nerve injury [68]. Complications of ligation and stripping include DVT, bleeding, hematoma, infection, and nerve injury. During the past decade, endovenous ablation therapy has largely replaced this classic ligation and stripping. Indications of this procedure have been restricted to patients with a large dilated and tortuous saphenous vein located immediately under the skin or to those with the aneurysmal enlargement at the SFJ, to patients with previous thrombophlebitis of the GSV or SSV where percutaneous placement of the laser fiber or radiofrequency catheter may not be possible, and to patients when open techniques must be used for vein removal.

Stab phlebectomy (ambulatory or hook phlebectomy or mini-phlebectomy) includes the removal or avulsion of varicose veins through small stab wounds or through a puncture hole made with a larger needle $[69,70]$. This procedure was performed in conjunction with saphenous vein ligation and stripping in the past. Currently, this is performed with saphenous vein ablation, either during the same procedure or at a later stage.

\section{Sclerotherapy}

Sclerotherapy is the least invasive percutaneous tech- nique using chemical irritants to close unwanted veins. Several sclerosants are available, including detergents (e.g., sodium morrhuate, ethanolamine oleate, sodium tetradecyl sulfate, and polidocanol), osmotic agents (e.g., hypertonic saline, hypertonic dextrose saline, and sodium salicylate), and chemical agents (e.g., polyiodinated iodine, chromated glycerin, and ethanol). The sclerosing agent is administered as a liquid or mixed with air or $\mathrm{CO}_{2} / \mathrm{O}_{2}$ to create a foam. Sclerotherapy can be used primarily or in conjunction with a surgical procedure in patients with CVI. Telangiectases, reticular veins, small varicose veins, and venous segments with reflux can be treated with sclerotherapy.

Ultrasound-guided foam sclerotherapy (UGFS) with polidocanol is currently preferred [71]. Generally, tumescent anesthesia is not required during UGFS. Because of the nitrogen gas, transient neurologic adverse effects, such as visual disturbance, migraine-like headache, or confusion, may occur, but they are rare [72]. The most common complication is hyperpigmentation; however, most resolve by 1 year after therapy. In the recently published study where 214 patients with CEAP class $\mathrm{C} 2$ $\mathrm{C}_{4}$ were randomized to receive either endovenous laser ablation (EVLA), surgery, or UGFS, perioperative pain was significantly reduced and sick leave was shorter after UGFS; however, GSV recanalization was highest in the UGFS group (51\%) during 1 year of follow-up [73].

\section{Endovenous thermal ablation}

There are two types of thermal ablation therapy: EVLA and RFA. Both are guided ultrasounds. The mechanism involves a heat generator that causes local thermal injury to the vein wall leading to thrombosis and fibrosis.

Both are frequently used for GSV reflux and have substituted the surgical procedure because of reduced convalescence and pain but similar efficacy [74-76]. On a meta-analysis, EVLA and RFA showed the same safety and efficacy in terms of quality of life, occlusion, thrombophlebitis, hematoma, and recanalization after 1 year [77].

Tumescent anesthesia is required for this procedure. Tumescent anesthesia is a technique used to deliver high-volume but low-dose anesthetic. Tumescent anesthesia solution usually consists of $445 \mathrm{~mL}$ of $0.9 \%$ saline, $50 \mathrm{~mL}$ of $1 \%$ lidocaine with 1:100,000 epinephrine, and $5 \mathrm{~mL}$ of $8.4 \%$ sodium bicarbonate. This solution is 
infiltrated into the perivenous area along the GSV (usually within the N2 compartment). This reduces pain, provides good hemostasis, prevents burn and nerve damage by creating a heat sink, and enhances heat transmission by compressing the vein close to the heat generator. With skillful tumescent application, larger veins may be ablated successfully.

The most common complication is bruising, which is observed in up to $75 \%$ of patients receiving ablation therapy. Other potential but rare complications include superficial vein thrombosis, DVT (especially EHIT), skin burn, pigmentation, and nerve injury. Arteriovenous fistula has been reported after perforator ablation [78].

\section{Stent implantation, bypass surgery, and valvuloplasty}

Catheter-based interventions such as stent implantation or surgical bypass may be considered to treat some patients with chronic occlusions of the iliac vein with advanced CVI symptoms who did not respond to other therapies.

Surgical reconstruction of the valves that involves tightening the valve by commissural apposition of the deep veins, and valve transfer procedures, where a segment of the patent valve from brachial or axillary vein interposes into the vein with an incompetent valve, are used to treat valvular incompetence.

\section{CONCLUSIONS}

CVI of the lower extremities is a relatively common but frequently underdiagnosed medical problem. Because it is associated with a wide clinical spectrum, it is important to approach patients with suspicion of the condition. A solid understanding of normal venous anatomy and function is needed to understand and diagnose the pathophysiology of CVI properly. Although anatomical evaluation using CT or MR may be sufficient to diagnose a patient with lower extremity arterial disease, functional evaluation using DUS is essential to diagnose patients with CVI. Compression stockings are the mainstay for conservative management, but low compliance is a major hurdle for this therapy. Earlier use of venous ablation therapy should be considered in symptomatic patients. For severe symptomatic patients with iliac vein compression or stenosis, the iliac vein stenting proce- dure can improve symptoms significantly.

\section{Conflict of interest}

No potential conflict of interest relevant to this article was reported.

\section{REFERENCES}

1. Raju S, Neglen P. Clinical practice. Chronic venous insufficiency and varicose veins. N Engl J Med 2009;360:23192327.

2. Eberhardt RT, Raffetto JD. Chronic venous insufficiency. Circulation 2014;130:333-346.

3. Baliyan V, Tajmir S, Hedgire SS, Ganguli S, Prabhakar AM. Lower extremity venous reflux. Cardiovasc Diagn Ther 2016;6:533-543.

4. Santler B, Goerge T. Chronic venous insufficiency: a review of pathophysiology, diagnosis, and treatment. J Dts

5. Callam MJ. Epidemiology of varicose veins. Br J Surg 1994;81:167-173.

6. Evans CJ, Fowkes FG, Ruckley CV, Lee AJ. Prevalence of varicose veins and chronic venous insufficiency in men and women in the general population: Edinburgh Vein Study. J Epidemiol Community Health 1999:53:149-153.

7. Kurz X, Kahn SR, Abenhaim L, et al. Chronic venous disorders of the leg: epidemiology, outcomes, diagnosis and management. Summary of an evidence-based report of the VEINES task force. Venous Insufficiency Epidemiologic and Economic Studies. Int Angiol 1999;18:83-102.

8. Brand FN, Dannenberg AL, Abbott RD, Kannel WB. The epidemiology of varicose veins: the Framingham Study. Am J Prev Med 1988;4:96-101.

9. Scott TE, LaMorte WW, Gorin DR, Menzoian JO. Risk factors for chronic venous insufficiency: a dual case-control study. J Vasc Surg 1995;22:622-628.

10. Fowkes FG, Lee AJ, Evans CJ, Allan PL, Bradbury AW, Ruckley CV. Lifestyle risk factors for lower limb venous reflux in the general population: Edinburgh Vein Study. Int J Epidemiol 2001;30:846-852.

11. Sadick NS. Predisposing factors of varicose and telangiectatic leg veins. J Dermatol Surg Oncol 1992;18:883-886.

12. 13. Park TY, Jung JW, Choi JC, et al. Epidemiological trend of pulmonary thromboembolism at a tertiary hospital in Korea. Korean J Intern Med 2017;32:1037-1044.

13. Morrone D, Morrone V. Acute pulmonary embolism: fo- 
cus on the clinical picture. Korean Circ J 2018;48:365-381.

14. Criqui MH, Jamosmos M, Fronek A, et al. Chronic venous disease in an ethnically diverse population: the San Diego Population Study. Am J Epidemiol 2003;158:448-456.

15. Bergan JJ, Schmid-Schonbein GW, Smith PD, Nicolaides AN, Boisseau MR, Eklof B. Chronic venous disease. N Engl J Med 2006;355:488-498.

16. Kahn SR, Comerota AJ, Cushman M, et al. The postthrombotic syndrome: evidence-based prevention, diagnosis, and treatment strategies: a scientific statement from the American Heart Association. Circulation 2014;130:16361661.

17. Caggiati A, Bergan JJ, Gloviczki P, et al. Nomenclature of the veins of the lower limb: extensions, refinements, and clinical application. J Vasc Surg 2005;41:719-724.

18. Caggiati A, Bergan JJ, Gloviczki P, et al. Nomenclature of the veins of the lower limbs: an international interdisciplinary consensus statement. J Vasc Surg 2002;36:416-422.

19. Caggiati A. Fascial relationships of the long saphenous vein. Circulation 1999;100:2547-2549.

20. Caggiati A. Fascial relationships of the short saphenous vein. J Vasc Surg 2001;34:241-246.

21. Cavezzi A, Labropoulos N, Partsch H, et al. Duplex ultrasound investigation of the veins in chronic venous disease of the lower limbs: UIP consensus document. Part II. Anatomy. Eur J Vasc Endovasc Surg 2006;31:288-299.

22. Wendell-Smith CP. Fascia: an illustrative problem in international terminology. Surg Radiol Anat 1997;19:273-277.

23. Theivacumar NS, Darwood RJ, Gough MJ. Endovenous laser ablation (EVLA) of the anterior accessory great saphenous vein (AAGSV): abolition of sapheno-femoral reflux with preservation of the great saphenous vein. Eur J Vasc Endovasc Surg 2009;37:477-481.

24. Min RJ, Khilnani NM, Golia P. Duplex ultrasound evaluation of lower extremity venous insufficiency. J Vasc Interv Radiol 2003;14:1233-1241.

25. Johnson BF, Manzo RA, Bergelin RO, Strandness DE Jr. Relationship between changes in the deep venous system and the development of the postthrombotic syndrome after an acute episode of lower limb deep vein thrombosis: a one- to six-year follow-up. J Vasc Surg 1995;21:307312.

26. Delis KT, Bountouroglou D, Mansfield AO. Venous claudication in iliofemoral thrombosis: long-term effects on venous hemodynamics, clinical status, and quality of life. Ann Surg 2004;239:118-126.
27. Razavi MK, Jaff MR, Miller LE. Safety and effectiveness of stent placement for iliofemoral venous outflow obstruction: systematic review and meta-analysis. Circ Cardiovasc Interv 2015;8:e002772.

28. Kibbe MR, Ujiki M, Goodwin AL, Eskandari M, Yao J, Matsumura J. Mliac vein compression in an asymptomatic patient population. J Vasc Surg 2004;39:937-943.

29. Kim JY, Choi D, Ko YG, Park S, Jang Y, Lee DY. Treatment of May-Thurner syndrome with catheter-guided local thrombolysis and stent insertion. Korean Circ J 2004;34:655-659.

30. Lamont JP, Pearl GJ, Patetsios P, et al. Prospective evaluation of endoluminal venous stents in the treatment of the May-Thurner syndrome. Ann Vasc Surg 2002;16:61-64.

31. O'Sullivan GJ, Semba CP, Bittner CA, et al. Endovascular management of iliac vein compression (May-Thurner) syndrome. J Vasc Interv Radiol 2000;11:823-836.

32. Koo S, Fan CM. Pelvic congestion syndrome and pelvic varicosities. Tech Vasc Interv Radiol 2014;17:90-95.

33. Labropoulos N, Leon L, Kwon S, et al. Study of the venous reflux progression. J Vasc Surg 2005;41:291-295.

34. Czarniawska-Grzesinska M, Bruska M. Number of valves in superficial veins of the leg. Folia Morphol (Warsz) 1999;58:233-237.

35. Tretbar LL. Deep veins. Dermatol Surg 1995;21:47-51.

36. Arnoldi CC. Venous pressure in the leg of healthy human subjects at rest and during muscular exercise in the nearly erect position. Acta Chir Scand 1965;130:570-583.

37. Labropoulos N, Volteas N, Leon M, et al. The role of venous outflow obstruction in patients with chronic venous dysfunction. Arch Surg 1997;132:46-51.

38. Katz ML, Comerota AJ, Kerr RP, Caputo GC. Variability of venous-hemodynamics with daily activity. J Vasc Surg 1994;19:361-365.

39. Rutherford RB, Padberg FT Jr, Comerota AJ, Kistner RL, Meissner MH, Moneta GL. Venous severity scoring: an adjunct to venous outcome assessment. J Vasc Surg 2000;31:1307-1312.

40. Scuderi A, Raskin B, Al Assal F, et al. The incidence of venous disease in Brazil based on the CEAP classification. Int Angiol 2002;21:316-321.

41. Gloviczki P, Comerota AJ, Dalsing MC, et al. The care of patients with varicose veins and associated chronic venous diseases: clinical practice guidelines of the Society for Vascular Surgery and the American Venous Forum. J Vasc Surg 2011;53(5 Suppl):2S-48S. 
42. Nicolaides AN, Allegra C, Bergan J, et al. Management of chronic venous disorders of the lower limbs: guidelines according to scientific evidence. Int Angiol 2008;27:1-59.

43. Christopoulos D, Nicolaides AN, Szendro G. Venous reflux: quantification and correlation with the clinical severity of chronic venous disease. Br J Surg 1988;75:352-356.

44. Criado E, Farber MA, Marston WA, Daniel PF, Burnham $\mathrm{CB}$, Keagy BA. The role of air plethysmography in the diagnosis of chronic venous insufficiency. J Vasc Surg 1998;27:660-670.

45. Cai L, Bear JE. Peering deeply inside the branch. J Cell Biol 2008;180:853-855.

46. Cho ES, Kim JH, Kim S, et al. Computed tomographic venography for varicose veins of the lower extremities: prospective comparison of $80-\mathrm{kVp}$ and conventional 120kVp protocols. J Comput Assist Tomogr 2012;36:583-590.

47. Kim SY, Park EA, Shin YC, et al. Preoperative determination of anatomic variations of the small saphenous vein for varicose vein surgery by three-dimensional computed tomography venography. Phlebology 2012;27:235-241.

48. Uhl JF. Three-dimensional modelling of the venous system by direct multislice helical computed tomography venography: technique, indications and results. Phlebology 2012;27:270-288.

49. Markel A, Meissner MH, Manzo RA, Bergelin RO, Strandness DE Jr. A comparison of the cuff deflation method with Valsalva's maneuver and limb compression in detecting venous valvular reflux. Arch Surg 1994;129:701-705.

50. Coleridge-Smith P, Labropoulos N, Partsch H, Myers K, Nicolaides A, Cavezzi A. Duplex ultrasound investigation of the veins in chronic venous disease of the lower limbs: UIP consensus document. Part I. Basic principles. Eur J Vasc Endovasc Surg 2006;31:83-92.

51. Neglen P, Egger JF 3rd, Olivier J, Raju S. Hemodynamic and clinical impact of ultrasound-derived venous reflux parameters. J Vasc Surg 2004;40:303-310.

52. Neglen P. Chronic deep venous obstruction: definition, prevalence, diagnosis, management. Phlebology 2008;23:149-157.

53. Neglen P, Raju S. Intravascular ultrasound scan evaluation of the obstructed vein. J Vasc Surg 2002;35:694-700.

54. Mayberry JC, Moneta GL, DeFrang RD, Porter JM. The influence of elastic compression stockings on deep venous hemodynamics. J Vasc Surg 1991;13:91-99.

55. Ibegbuna V, Delis KT, Nicolaides AN, Aina O. Effect of elastic compression stockings on venous hemodynamics during walking. J Vasc Surg 2003;37:420-425.

56. Sajid MS, Desai M, Morris RW, Hamilton G. Knee length versus thigh length graduated compression stockings for prevention of deep vein thrombosis in postoperative surgical patients. Cochrane Database Syst Rev 2012;5:CDoo7162.

57. Franks PJ, Oldroyd MI, Dickson D, Sharp EJ, Moffatt CJ. Risk factors for leg ulcer recurrence: a randomized trial of two types of compression stocking. Age Ageing 1995;24:490-494.

58. Raju S, Hollis K, Neglen P. Use of compression stockings in chronic venous disease: patient compliance and efficacy. Ann Vasc Surg 2007;21:790-795.

59. Jull AB, Mitchell N, Arroll J, et al. Factors influencing concordance with compression stockings after venous leg ulcer healing. J Wound Care 2004;13:90-92.

6o. Erickson CA, Lanza DJ, Karp DL, et al. Healing of venous ulcers in an ambulatory care program: the roles of chronic venous insufficiency and patient compliance. J Vasc Surg 1995;22:629-636.

61. Kiev J, Noyes LD, Rice JC, Kerstein MD. Patient compliance with fitted compression hosiery monitored by photoplethysmography. Arch Phys Med Rehabil 1990;71:376379.

62. Pittler MH, Ernst E. Horse chestnut seed extract for chronic venous insufficiency. Cochrane Database Syst Rev 2012;11:CDoo3230.

63. Guilhou JJ, Dereure O, Marzin L, et al. Efficacy of Daflon $500 \mathrm{mg}$ in venous leg ulcer healing: a double-blind, randomized, controlled versus placebo trial in 107 patients. Angiology 1997;48:77-85.

64. Coleridge-Smith P, Lok C, Ramelet AA. Venous leg ulcer: a meta-analysis of adjunctive therapy with micronized purified flavonoid fraction. Eur J Vasc Endovasc Surg 2005;30:198-208.

65. Martinez MJ, Bonfill X, Moreno RM, Vargas E, Capella D. Phlebotonics for venous insufficiency. Cochrane Database Syst Rev 2005;3:CDoo3229.

66. Jull A, Waters J, Arroll B. Pentoxifylline for treatment of venous leg ulcers: a systematic review. Lancet 2002;359:1550-1554.

67. Falanga V, Fujitani RM, Diaz C, et al. Systemic treatment of venous leg ulcers with high doses of pentoxifylline: efficacy in a randomized, placebo-controlled trial. Wound Repair Regen 1999;7:208-213.

68. Holme JB, Skajaa K, Holme K. Incidence of lesions of the 
saphenous nerve after partial or complete stripping of the long saphenous vein. Acta Chir Scand 1990;156:145148.

69. Goren G, Yellin AE. Minimally invasive surgery for primary varicose veins: limited invaginated axial stripping and tributary (hook) stab avulsion. Ann Vasc Surg 1995;9:401414 .

70. Bergan JJ. Varicose veins: hooks, clamps, and suction. Application of new techniques to enhance varicose vein surgery. Semin Vasc Surg 2002;15:21-26.

71. Breu FX, Guggenbichler S. European consensus meeting on foam sclerotherapy, April, 4-6, 2003, Tegernsee, Germany. Dermatol Surg 2004;30:709-717.

72. Ceulen RP, Sommer A, Vernooy K. Microembolism during foam sclerotherapy of varicose veins. N Engl J Med 2008;358:1525-1526.

73. Venermo M, Saarinen J, Eskelinen E, et al. Randomized clinical trial comparing surgery, endovenous laser ablation and ultrasound-guided foam sclerotherapy for the treatment of great saphenous varicose veins. Br J Surg 2016;103:1438-1444.
74. Comerota A, Lurie F. Pathogenesis of venous ulcer. Semin Vasc Surg 2015;28:6-14.

75. Darwood RJ, Theivacumar N, Dellagrammaticas D, Mavor AI, Gough MJ. Randomized clinical trial comparing endovenous laser ablation with surgery for the treatment of primary great saphenous varicose veins. Br J Surg 2008;95:294-301.

76. Paravastu SC, Horne M, Dodd PD. Endovenous ablation therapy (laser or radiofrequency) or foam sclerotherapy versus conventional surgical repair for short saphenous varicose veins. Cochrane Database Syst Rev 2016;11:CDo10878.

77. He G, Zheng C, Yu MA, Zhang H. Comparison of ultrasound-guided endovenous laser ablation and radiofrequency for the varicose veins treatment: an updated meta-analysis. Int J Surg 2017;39:267-275.

78. Bacon JL, Dinneen AJ, Marsh P, Holdstock JM, Price BA, Whiteley MS. Five-year results of incompetent perforator vein closure using TRans-Luminal Occlusion of Perforator. Phlebology 2009;24:74-78. 